ISSN 0103-9954

\title{
PRODUÇÃO DE SERAPILHEIRA E TRANSFERÊNCIA DE NUTRIENTES EM ÁREA DE SEGUNDA ROTAÇÃO COM FLORESTA DE Pinus taeda L. NO MUNICÍPIO DE CAMBARÁ DO SUL, RS
}

\author{
LITTER PRODUCTION AND NUTRIENTS TRANSFER IN A SECOND ROTATION AREA WITH \\ Pinus taeda L. FOREST IN CAMBARÁ DO SUL, RS
}

\author{
Mauro Valdir Schumacher ${ }^{1}$ Márcio Viera ${ }^{2}$ Rudi Witschoreck ${ }^{3}$ \\ RESUMO
}

Objetivou-se avaliar a transferência de serapilheira e nutrientes das copas ao solo em área de segunda rotação com floresta de Pinus taeda L. num período de 3 anos ( $5^{\circ}$ ao $7^{0}$ ano de idade) no município de Cambará do Sul, RS. Para tanto, foram alocadas três parcelas de $48 \mathrm{~m}$ x $50 \mathrm{~m}$, cada uma com cinco coletores de $1 \mathrm{~m}^{2}$. Todo material depositado foi coletado mensalmente entre abril de 2004 e março de 2007. Após cada coleta, o material foi identificado e levado para o laboratório de Ecologia Florestal da Universidade Federal de Santa Maria onde posteriormente foi seco em estufa, pesado, moído e analisado quimicamente quanto aos teores de macro e micronutrientes. A deposição média anual de serapilheira foi de 4.519,1 $\mathrm{kg} \mathrm{ha}^{-1}$, mostrando-se variável no decorrer dos três anos de estudos. $\mathrm{O}$ aporte total de macronutrientes ao solo, em $\mathrm{kg}$ ha $^{-1}$ ano $^{-1}$, foi de: 28,7 de Ca; 27,3 de N; 4,8 de Mg; 4,6 de K; 2,4 de S e 1,8 de P e o aporte de micronutrientes, em g ha ${ }^{-1}$ ano $^{-1}$, foi de: 6.689,7 de Mn; 1.092,9 de Fe; 142,8 de Zn; 60,0 de B e 16,7 de Cu.

Palavras-chave: nutrição florestal; sustentabilidade florestal; produção florestal.

\section{ABSTRACT}

This study had the objective of evaluating the litter and nutrients transfer to the soil in a second rotation area with Pinus taeda L. forest, during three years $\left(5^{\text {th }}\right.$ to $7^{\text {th }}$ year) in Cambará do Sul, RS. Three plots $(48 \mathrm{~m} \times 50 \mathrm{~m})$ were allocated, each one with 5 collectors $\left(1 \mathrm{~m}^{2}\right)$. All the material deposited was collected monthly between April, 2004 and March, 2007. After each collection, the material was identified and sent to the Forest Ecology Laboratory at Universidade Federal de Santa Maria, where it was dried in a stove, weighed, milled and analyzed considering macro and micronutrient amounts. The litter annual average deposition was $4.519,1 \mathrm{~kg} \mathrm{ha}^{-1}$, showing to be variable during the three years of study. The total return of macronutrients to the soil ( $\mathrm{kg} \mathrm{ha}^{-1}$ year $^{-1}$ ) was 28,7 of Ca; 27,3 of N; 4,8 of Mg; 4,6 of K; 2,4 of S and 1,8 of $\mathrm{P}$ and the total of micronutrients $\left(\mathrm{g} \mathrm{ha}^{-1} \mathrm{year}^{-1}\right.$ ) was 6.689,7 of Mn; 1.092,9 of Fe; 142,8 of Zn; 60,0 of B and16,7 of $\mathrm{Cu}$.

Keywords: forest nutrition; forest sustainability; forest production.

\section{INTRODUÇÃO}

As atividades de florestamento e reflorestamento com espécies do gênero Pinus foram intensificadas a partir da segunda metade da década de sessenta, após a promulgação da lei dos incentivos fiscais. Extensas áreas foram ocupadas predominantemente com Pinus taeda L. e Pinus elliotti Engelm. var. elliotti, constituindo hoje bases de importantes atividades industriais como produção de celulose e papel, embalagens, aglomerados, mobiliário, compensados, chapas dentre outras (FERREIRA et al., 2004). Estimase em aproximadamente 1.824.000 ha a área ocupada por espécies de pinus no Brasil. Na região sul estimase em 1.400.000 ha a área plantada, com a seguinte distribuição: 687.000 ha no Paraná, 531.000 ha em Santa Catarina e 182.000 ha no Rio Grande do Sul (ABRAF, 2007).

As espécies do gênero Pinus, são conhecidas por sua baixa exigência nutricional, podendo ser

1. Engenheiro Florestal, Dr., Professor Associado do Departamento de Ciências Florestais, Centro de Ciências Rurais, Universidade Federal de Santa Maria, Cidade Universitária "Prof. Mariano da Rocha Filho”, Av. Roraima, 1000, Bairro Camobi, CEP 97015-900, Santa Maria (RS). schumacher@pesquisador.cnpq.br

2. Acadêmico do Curso de Engenharia Florestal, Centro de Ciências Rurais, Universidade Federal de Santa Maria, Cidade Universitária “Prof. Mariano da Rocha Filho”, Av. Roraima, 1000, Bairro Camobi, CEP 97015-900, Santa Maria (RS). vieraflorestal@yahoo.com.br

3. Engenheiro Florestal, M.Sc. pelo Programa de Pós-Graduação em Engenharia Florestal, Centro de Ciências Rurais, Universidade Federal de Santa Maria, Cidade Universitária "Prof. Mariano da Rocha Filho”, Av. Roraima, 1000, Bairro Camobi, CEP 97015-900, Santa Maria (RS).rwitschoreck@yahoo.com.br.

Recebido para publicação em 10/10/2007 e aceito em 15/10/2008. 
encontradas crescendo em ambientes extremamente pobres em nutrientes, nos quais, apesar da produção estar aquém do satisfatório, as plantas demonstram uma capacidade extraordinária de adaptação com um bom gerenciamento dos escassos recursos nutricionais.

Em conseqüência da implantação de povoamentos em solos extremamente pobres, o estudo do ciclo de nutrientes nesses locais é de importância fundamental, possibilitando a previsão de situações que poderiam ser críticas a médio e longo prazo, tanto em relação à produtividade, como em relação às características do solo.

A contínua exportação de nutrientes por meio da colheita reduz a capacidade produtiva do sítio e desestabiliza o ecossistema, comprometendo a produtividade florestal dos futuros ciclos de produção (REIS e BARROS, 1990; PEREIRA et al., 1984).

Para Vital et al. (2004), é mediante a produção de serapilheira que ocorre parte do processo de retorno de matéria orgânica e de nutrientes para o solo florestal, sendo ela considerada o meio mais importante de transferência de elementos essenciais da vegetação (nutrientes) para o solo. Segundo Schumacher et al. (2004) essa camada de serapilheira que se acumula sob povoamentos de pínus, funciona como uma grande esponja sobre o solo, com capacidade de reter a água da chuva, reduzir a evaporação e as variações bruscas de temperatura do solo, assim evitando a erosão, melhorando a estrutura do solo e promovendo a ciclagem de nutrientes.

Sendo assim, a hipótese de que a serapilheira é o principal meio de transporte de nutrientes da planta para o solo, deve ser considerada, levando a crer que sua permanência no povoamento reduz em parte o déficit de nutrientes no solo que ocorre em conseqüência da exportação da biomassa durante colheita florestal.

O presente trabalho teve por objetivo estimar a quantidade de serapilheira produzida, bem como a quantidade de nutrientes devolvidos ao piso florestal em área de segunda rotação com floresta de Pinus taeda L. num período de três anos (5ํㅜ ao $7^{0}$ ano de idade), plantada em Cambará do Sul, RS.

\section{MATERIAL E MÉTODO}

\section{Caracterização da área de estudo}

O presente estudo foi realizado em área de segunda rotação com floresta de pínus, localizado em área pertencente à empresa Cambará S. A., situado nas coordenadas geográficas de $28^{\circ} 52^{\prime}$ 'de latitude Sul e $50^{\circ}$ 08' de longitude Oeste, numa altitude média de 1089 m. A cidade de Cambará do Sul localiza-se no nordeste do Estado do Rio Grande do Sul, na região fisiográfica dos Campos de Cima da Serra (Figura 1).

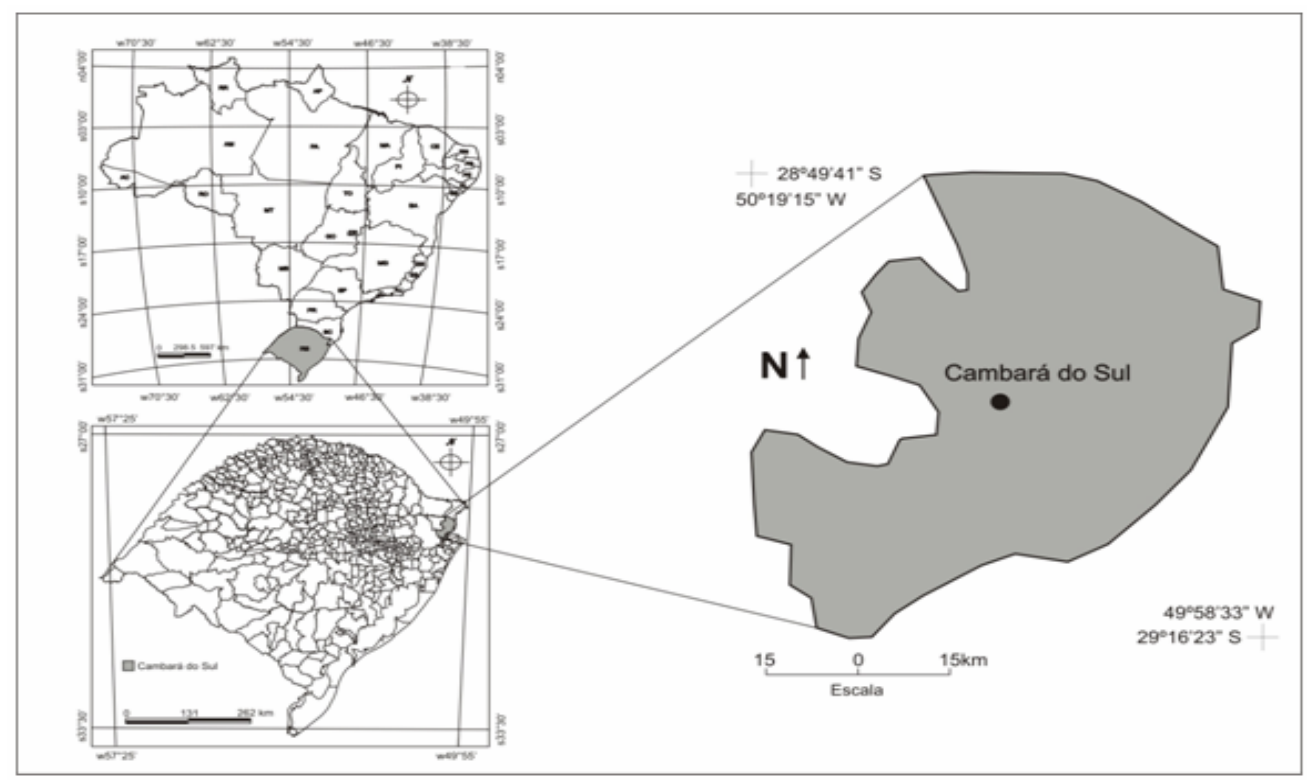

FIGURA 1: Localização do município de Cambará do Sul, RS. (Fonte: Modificado de FEE, 2008).

FIGURE 1: Location of Cambará do Sul, RS. 
Segundo a classificação climática de Köppen, o tipo de clima fundamental predominante é o Cfb (temperado úmido), a precipitação média na região é de $1.700 \mathrm{~mm}$, bem distribuída durante o ano. A temperatura média anual é de aproximadamente $15^{\circ} \mathrm{C}$, sendo que a média das temperaturas máximas é de $22^{\circ} \mathrm{C}$ e a média das temperaturas mínimas é de $8,5^{\circ} \mathrm{C}$ (MORENO, 1961). Conforme Motta et al. (1971), os ventos dominantes na região são alísios, ou seja, sopra do mar para a terra, em conseqüência da região situar-se próximo ao litoral norte do estado do Rio Grande do Sul.

Quanto ao solo, os atributos químicos podem ser observados pela Tabela 1, conforme estudo de Schumacher et al. (2007). O material de origem é rocha basáltica, resultante do derrame basáltico do Triássico Superior, predominando solos rasos com horizonte A de coloração escura, com baixa saturação de bases e teor elevado de alumínio trocável. O solo da região pertence à Unidade de Mapeamento Bom Jesus e é classificado como Cambissolo Húmico alumínico típico (BRASIL, 1973; STRECK et al,. 2002).

A floresta, do presente estudo, foi implantada em área de corte raso onde os resíduos do primeiro povoamento (Pinus taeda L.) foram enleirados. Para o plantio, utilizou-se coroamento $(60 \mathrm{~cm} \mathrm{x} 60 \mathrm{~cm})$ como preparo mínimo de solo. O plantio do povoamento decorreu-se no período de inverno do ano de 1999, com mudas clonais produzidas em tubetes e optando-se por um espaçamento de $3 \mathrm{~m}$ x $2 \mathrm{~m}$. Aos 5 anos de idade, todas as árvores sofreram poda (desrama) até 3,0 m de altura.

TABELA 1: Características químicas do solo na área experimental.

TABLE 1: Soil chemical characteristics in the experimental area.

\begin{tabular}{|c|c|c|c|c|c|c|c|c|c|c|c|c|}
\hline \multirow{2}{*}{$\begin{array}{l}\text { Prof. } \\
\text { (cm) }\end{array}$} & \multirow{2}{*}{ Arg. (\%) } & \multirow{2}{*}{$\begin{array}{c}\mathrm{pH} \\
\left(\mathrm{CaCl}_{2}\right)\end{array}$} & \multirow{2}{*}{$\begin{array}{l}\text { MO } \\
(\%)\end{array}$} & $\mathrm{P}$ & $\mathrm{K}$ & $\mathrm{Al}$ & $\mathrm{Ca}$ & Mg & \multirow{2}{*}{\begin{tabular}{|c|} 
Sat. (\%) \\
$\mathrm{Al}$
\end{tabular}} & \multirow{2}{*}{\multicolumn{3}{|c|}{$\frac{\mathrm{Fe}}{\mathrm{mg} \mathrm{dm}^{-3}}$}} \\
\hline & & & & \multicolumn{2}{|c|}{$\mathrm{mg} \mathrm{dm}^{-3}$} & \multicolumn{3}{|c|}{$\mathrm{cmol}_{\mathrm{c}} \mathrm{dm}^{-3}$} & & & & \\
\hline $0-10$ & 37,0 & 3,65 & 5,28 & 3,82 & 50,67 & 7,12 & 1,20 & 0,37 & 81,6 & 3,96 & 89,07 & 13,09 \\
\hline & & 3,72 & 5,16 & 2,56 & 38,67 & 7,04 & 1,12 & 0,23 & 3,7 & 3,80 & 3,73 & 4,66 \\
\hline & & 3,72 & 4,70 & 1,99 & 26,67 & 7,14 & 0,87 & 0,21 & 87 & 4,40 & 75,16 & 3,74 \\
\hline $30-40$ & & 3,73 & 3,78 & 1,57 & 20,00 & 6,69 & 0,50 & 0,13 & 90,3 & 4,81 & 68,41 & 1,01 \\
\hline $40-50$ & & 3,74 & 2,97 & 1,47 & 17,33 & 7,18 & 0,48 & 0,16 & 91,4 & 4,94 & 71,03 & 3,04 \\
\hline $50-80$ & 54,3 & 3,77 & 2,38 & 1,23 & 18,67 & 7,09 & 0,36 & 0,13 & 92,9 & 4,69 & 84,89 & 2,34 \\
\hline
\end{tabular}

Fonte: Schumacher et al. (2007).

\section{Metodologia do estudo}

Em condições de sítio semelhantes, foram alocadas, de forma aleatória, três parcelas de 48 m x 50 m, nelas foram distribuídos vinte coletores de serapilheira, cinco por parcela, sendo duas na linha de plantio (1 e 2), duas na entrelinha de plantio (4 e 5) e uma na diagonal entre duas linhas de plantio (3), conforme Figura 2. Os coletores são do tipo bandeja, dispostos a $0,70 \mathrm{~m}$ de altura do solo, com uma área de coleta de $1 \mathrm{~m}^{2}$ cada.

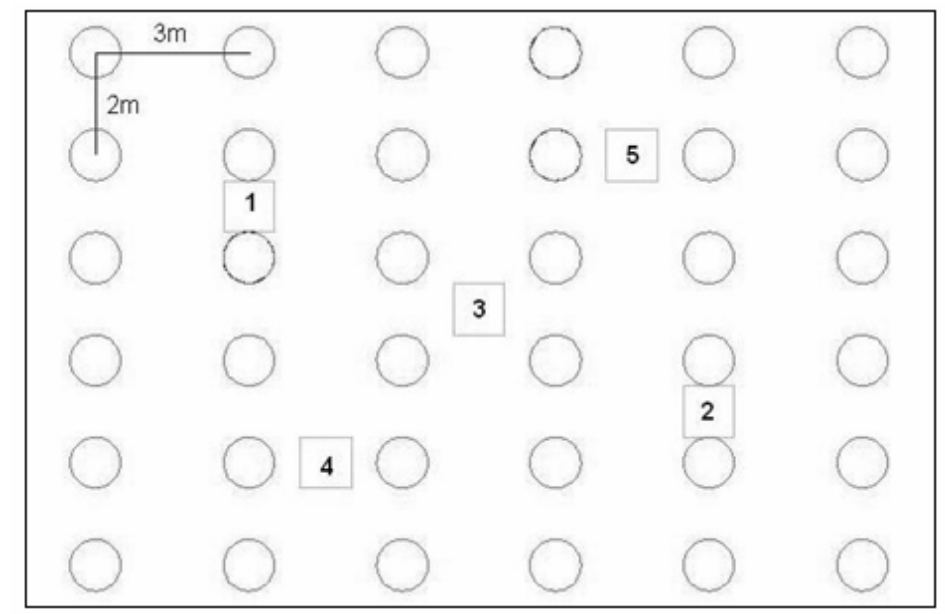

FIGURA 2: Croqui demonstrativo da distribuição dos coletores no interior da parcela amostral.

FIGURE 2: Sketch demonstration of the distribution of collectors within the sample plot.

Mensalmente coletou-se o material interceptado nos coletores, durante um período de 3 anos (abril de 2004 a março de 2007). O material recolhido foi acondicionado em embalagem plástica, devidamente 
identificado e enviado ao Laboratório de Ecologia Florestal, pertencente ao Departamento de Ciências Florestais da Universidade Federal de Santa Maria.

No laboratório, as amostras foram secas em estufa de circulação e renovação de ar a $70^{\circ} \mathrm{C}$, por um período de 72 horas, sendo posteriormente pesado em balança digital de precisão (0,01 g).

Para análise química, as amostras provenientes dos cinco coletores de cada parcela foram misturadas, formando uma amostra composta e moídas em moinho do tipo Wiley com peneira de 30 mesh. Nas amostras foram determinado os teores de nitrogênio pelo método Kjeldahl, fósforo e boro por espectrometria visível, potássio por fotometria de chama, enxofre por turbidimetria e o cálcio, magnésio, cobre, ferro, manganês e zinco por espectrofotometria de absorção atômica, seguindo a metodologia descrita por Tedesco et al. (1995).

Tomando por base os dados provenientes de cada coleta mensal de serapilheira, foram estimados a quantidade de matéria seca e nutrientes que retornam ao piso florestal, durante o quinto, sexto e sétimo ano do povoamento. Todas as análises estatísticas foram realizadas com o auxilio do programa estatístico Genes (CRUZ, 2001) ao nível de 5\% de probabilidade de erro, para a separação dos contrastes de médias utilizou-se o teste de Tukey.

\section{RESULTADOS E DISCUSSÃO}

\section{Produção de serapilheira}

A serapilheira, também conhecida como manta, constitui-se da camada de detritos vegetais (folhas, ramos, caules, cascas, frutos e flores), bem como restos de animais e material fecal, disposta na superfície do solo.

Essa serapilheira, para o presente estudo, em um povoamento de $P$. taeda, foi considerada durante um período de 3 anos ( $5^{\circ}$ ao $7^{\circ}$ ano de idade), sendo ela formada somente por acículas. A deposição de serapilheira (Tabela 2) aumentou com o passar do tempo devido ao progressivo desenvolvimento das plantas. No primeiro ano de estudo foi de 3,99 $\mathrm{Mg} \mathrm{ha}^{-1}$, no segundo ano foi de 4,72 $\mathrm{Mg} \mathrm{ha}^{-1}$ e no terceiro ano a deposição chegou a 4,84 $\mathrm{Mg} \mathrm{ha}^{-1}$. Na relação geral, os meses que mais influenciaram na deposição total foram abril, junho e setembro (mais de 38\%) e outubro o menos que influenciou (3,3\%).

Em plantios de Pinus taeda, com 15 anos de idade, na região de Ponta Grossa-PR, Koehler (1989) analisando três sítios diferentes, encontrou uma deposição média anual de $8,7 \mathrm{Mg} \mathrm{ha}^{-1}$ no sítio bom, 8,4 Mg ha $^{-1}$ no sítio médio e 6,5 $\mathrm{Mg}_{\text {ha }}{ }^{-1}$ no sítio ruim.

TABELA 2: Deposição mensal de serapilheira $\left(\mathrm{kg} \mathrm{ha}^{-1}\right)$ no período de abril/2004 a março/2007, em um povoamento de Pinus taeda, em área de segunda rotação. Cambará do Sul, RS.

TABLE 2: Litter monthly deposition $\left(\mathrm{kg} \mathrm{ha}^{-1}\right)$ from April/2004 to March/2007, in a Pinus taeda stand, in a second rotation year. Cambará do Sul, RS.

\begin{tabular}{lllllll}
\hline Mês & \multicolumn{1}{c}{$04-05^{1}$} & \multicolumn{1}{c}{$05-06$} & \multicolumn{1}{c|}{$06-07$} & \multicolumn{1}{c}{ Média } & \multicolumn{1}{c}{ Total } \\
\hline Abril & $362,2(9,1)$ & $565,5(12,0)$ & $809,8(16,7)$ & 579,1 & $1737,4(12,8)$ \\
Maio & $198,9(5,0)$ & $232,3(4,9)$ & $412,8(8,5)$ & 281,3 & $844,0(6,2)$ \\
Junho & $559,7(14,0)$ & $470,1(10,0)$ & $643,1(13,3)$ & 557,7 & $1673,0(12,3)$ \\
Julho & $405,2(10,2)$ & $659,3(14,0)$ & $532,2(11,0)$ & 532,2 & $1596,7(11,8)$ \\
Agosto & $96,6(2,4)$ & $508,3(10,8)$ & $233,3(4,8)$ & 279,4 & $838,2(6,2)$ \\
Setembro & $269,3(6,7)$ & $926,1(19,6)$ & $535,4(11,1)$ & 576,9 & $1730,8(12,8)$ \\
Outubro & $148,1(3,7)$ & $89,2(1,9)$ & $216,7(4,5)$ & 151,3 & $454,0(3,3)$ \\
Novembro & $197,3(4,9)$ & $160,4(3,4)$ & $234,6(4,8)$ & 197,5 & $592,4(4,4)$ \\
Dezembro & $169,4(4,2)$ & $153,6(3,3)$ & $269,1(5,6)$ & 197,4 & $592,1(4,4)$ \\
Janeiro & $263,5(6,6)$ & $234,1(5,0)$ & $269,0(5,6)$ & 255,5 & $766,6(5,7)$ \\
Fevereiro & $482,6(12,1)$ & $326,4(6,9)$ & $322,7(6,7)$ & 377,3 & $1131,8(8,3)$ \\
Março & $837,7(21,0)$ & $399,1(8,4)$ & $363,6(7,5)$ & 533,5 & $1600,5(11,8)$ \\
\hline Soma & $3990,7(100,0)$ & $4724,3(100,0)$ & $4842,4(100,0)$ & 4519,1 & $13557,4(100,0)$ \\
\hline
\end{tabular}

Em que: ${ }^{1}$ 04-05 (correspondem ao período de abril/2004 a março/2005); 05-06 (abril/2005 a março/2006) e 06-07 (abril/2006 a março/2007). Valores entre parênteses, refere-se à porcentagem de cada mês em relação ao total de serapilheira depositada naquele ano. 
No estudo realizado por Poggiani (1985), com ciclagem de nutrientes em ecossistemas de plantações florestais de eucaliptos (com 7 anos de idade) e pinus (com 11 anos de idade), o autor encontrou uma deposição de 4,5 $\mathrm{Mg} \mathrm{ha}^{-1}$ para Eucalyptus saligna, 7,1 $\mathrm{Mg} \mathrm{ha}^{-1}$ para Pinus oocarpa e 8,4 $\mathrm{Mg} \mathrm{ha}^{-1}$ para Pinus caribaea var. hondunensis.

Em talhões experimentais de Pinus taeda, Eucalyptus viminalis e Mimosa scabrella, plantados em área degradada pela extração de xisto betuminoso no Paraná, Poggiani et al. (1987), estudaram a deposição de serapilheira, a qual alcançou uma produção de 4,4; 2,8 e 4,8 $\mathrm{Mg} \mathrm{ha}^{-1}$ respectivamente.

Florestas situadas em regiões árticas ou alpinas produzem anualmente cerca de uma tonelada por hectare de serapilheira, florestas temperadas frias 3,5 toneladas, florestas temperadas quentes 5,5 toneladas e florestas equatoriais cerca de 11 toneladas (BRAY e GOHRAN, 1964).

As Figuras 3, 4 e 5 apresentam a deposição mensal de serapilheira por ano de observação, o comportamento da precipitação pluviométrica e a temperatura média mensal. No ano 1 (Figura 3), no período do verão, nota-se um aumento na temperatura e da deposição e uma baixa precipitação, podendo-se considerar que, nesse período, ocorreu um déficit hídrico e aliado a altas temperaturas poderia ter ocasionado a elevação da deposição como estratégia de sobrevivência das plantas, evitando assim, a perda de água por meio da alta intensidade transpiratória causada pelo calor.

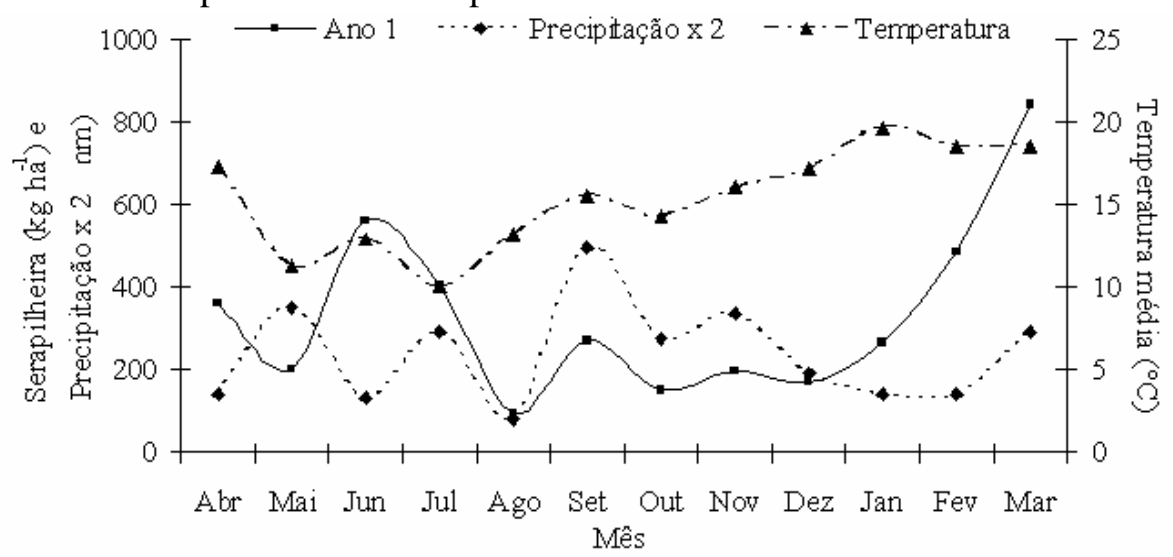

FIGURA 3: Variação no acúmulo de serapilheira $\left(\mathrm{kg} \mathrm{ha}^{-1}\right)$, da precipitação $(\mathrm{mm})$ e a temperatura média mensal $\left({ }^{\circ} \mathrm{C}\right)$, no período de $\mathrm{Abr} / 2004$ a Mar/2005.

FIGURE 3: Litter accumulation $\left(\mathrm{kg} \mathrm{ha}^{-1}\right)$, precipitation $(\mathrm{mm})$ and monthly average temperature $\left({ }^{\circ} \mathrm{C}\right)$ variation, from April/ 2004 to March/2005.

O pico de deposição ocorrido em setembro do ano 2 (Figura 4), pode estar relacionada com a diminuição abrupta da precipitação e da temperatura, o que poderia ocasionar estresse nas plantas, deixandoas debilitadas, ocasionando alteração nos processos biológicos naturais e conseqüentemente aumentando a deposição.

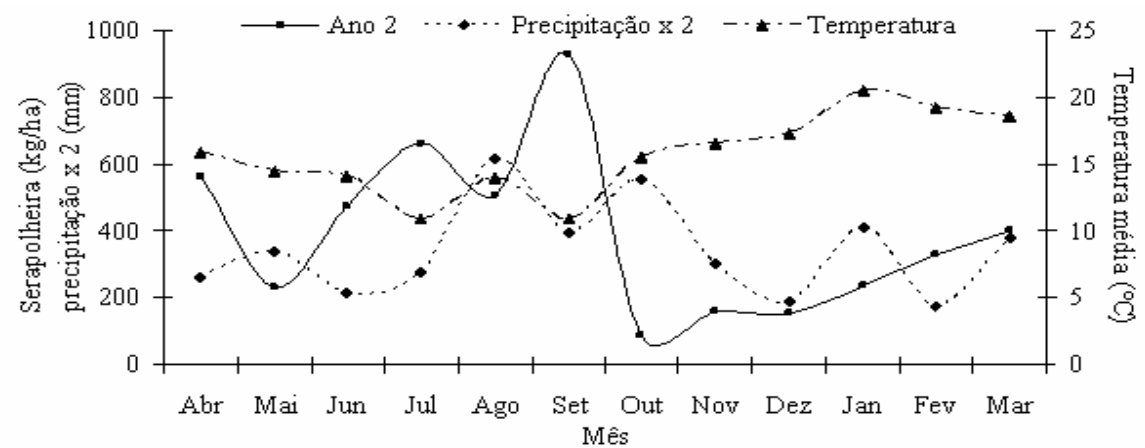

FIGURA 4: Variação no acúmulo de serapilheira $\left(\mathrm{kg} \mathrm{ha}^{-1}\right)$, da precipitação (mm) e a temperatura média mensal $\left({ }^{\circ} \mathrm{C}\right)$, no período de Abr./2005 a Mar./2006.

FIGURE 4: Litter accumulation $\left(\mathrm{kg} \mathrm{ha}^{-1}\right)$, precipitation $(\mathrm{mm})$ and monthly average temperature $\left({ }^{\circ} \mathrm{C}\right)$ variation, from April/ 2005 to March/2006. 
Na Figura 5, a deposição se mostrou semelhante aos outros 2 anos, com alguns picos nos meses de abril, junho e setembro, quando ocorreu pouca disponibilidade de água para as plantas, devido à baixa taxa de precipitação pluviométrica. A partir de outubro, iniciou-se um processo acelerado de deposição com o aumento da temperatura.

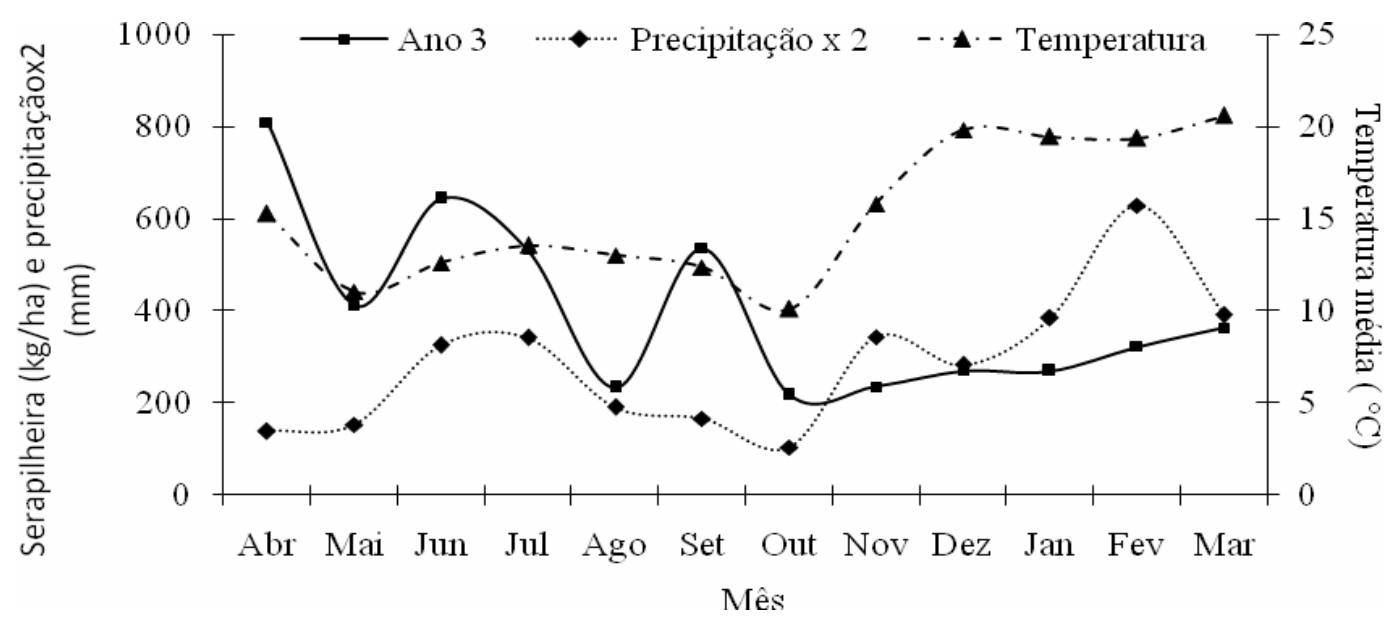

FIGURA 5: Variação no acúmulo de serapilheira $\left(\mathrm{kg} \mathrm{ha}^{-1}\right)$, da precipitação (mm) e a temperatura média mensal $\left({ }^{\circ} \mathrm{C}\right)$, no período de Abr./2006 a Mar./2007.

FIGURE 5: Litter accumulation $\left(\mathrm{kg} \mathrm{ha}^{-1}\right)$, precipitation $(\mathrm{mm})$ and monthly average temperature $\left({ }^{\circ} \mathrm{C}\right)$ variation, from April/ 2006 to March/2007.

A relação quantidade de serapilheira senescente e condições meteorológicas foram avaliadas pela análise de correlação de PEARSON (r) (Tabela 3), observando-se que somente a velocidade do vento ( $\mathrm{m} \mathrm{s}^{-1}$ ), dentre as variáveis climáticas, durante o segundo ano de estudo, correlacionou-se de forma direta com a deposição, apresentando um coeficiente $r$ igual a 0,41 , sendo este valor de correlação considerado médio.

A velocidade do vento durante o primeiro ano e a temperatura média mensal durante o segundo ano de estudo, apresentaram correlação inversa com a deposição, sendo que o coeficiente $r$ foi igual a $-0,40$ e 0,66, respectivamente. As outras variáveis meteorológicas não apresentaram correlação significativa com a deposição.

Cabe ressaltar que as variáveis climáticas utilizadas para averiguar possíveis correlações com a variação da deposição de serapilheira, são valores médios mensais. Sendo assim, a ocorrência de fatores climáticos extremos, como por exemplo, tempestades ocasionais, podem modificar pouco a média mensal das variáveis, mas podem acarretar um aumento acentuado na deposição naquele período, mascarando, nesses casos, a análise de correlação.

Por meio da Figura 6, podem-se observar a variação sazonal na deposição de serapilheira e a variação entre os 3 anos de estudos. Na estação primavera, a deposição foi baixa e aproximadamente igual para os 3 anos. Já nas demais estações, ela foi elevada e com grandes oscilações no decorrer do estudo.

TABELA 3: Análise de correlação de PEARSON (r) entre a deposição de serapilheira e variáveis meteorológicas. Cambará do Sul, RS.

TABLE 3: PEARSON correlation analysis (r) between litter deposition and meteorological variables. Cambará do Sul, RS.

\begin{tabular}{ccc|c|c|c|c|c}
\hline Período & $\mathrm{P}(\mathrm{mm})$ & $\mathrm{T}\left({ }^{\circ} \mathrm{C}\right)$ & $\mathrm{UR}(\%)$ & $\mathrm{V}\left(\mathrm{m} \mathrm{s}^{-1}\right)$ & $\mathrm{ETP}(\mathrm{mm})$ & $\mathrm{P}-\mathrm{ETP}(\mathrm{mm})$ \\
\hline Abr/04 - Mar/05 & $-0,04$ & 0,25 & 0,34 & $-0,40$ & $-0,23$ & 0,01 \\
$\mathrm{Abr} / 05-\mathrm{Mar} / 06$ & 0,002 & $-0,66$ & 0,27 & 0,41 & $-0,21$ & 0,06 \\
$\mathrm{Abr} / 06-\mathrm{Mar} / 07$ & $-0,21$ & $-0,23$ & 0,22 & 0,07 & 1 & - \\
\hline Abr/04 - Mar/07 & $-0,04$ & $-0,22$ & 0,267 & $-0,06$ & $-0,24$ & 0,09 \\
\hline
\end{tabular}

Em que: P (precipitação pluviométrica); T (temperatura); UR (umidade relativa); V (velocidade do vento); EVP (evapotranspiração) e P - ETP (precipitação pluviométrica - evapotranspiração); ${ }^{1}$ Falta de informações meteorológicas no período de abr/06 a mar/07. 
Essa grande diferença na deposição, entre as estações nos diferentes anos, se deve provavelmente a interferência de fatores climáticos adversos, que poderiam influenciar de maneira marcante a deposição, como mencionado anteriormente.

O povoamento apresentou uma magnitude sazonal média de deposição, seguindo a ordem estacional: inverno $=$ outono $>$ verão $>$ primavera. Sendo ela variável em cada ano de observação, não estando bem definida, em razão da juvenilidade das plantas.

Koehler (1989), estudando povoamentos de Pinus taeda, na região de Ponta Grossa, PR., encontrou maior produção de serapilheira no outono e a menor no período inverno-primavera. Nesse mesmo estudo, a autora encontrou uma correlação positiva e significativa entre a produção de serapilheira e a umidade relativa do ar. Melo e Resck (2002), estudando a deposição de serapilheira em três deferentes procedências de Pinus caribaea, com 16 anos de idade, constatou que a maior queda de acículas ocorre no período seco do ano.

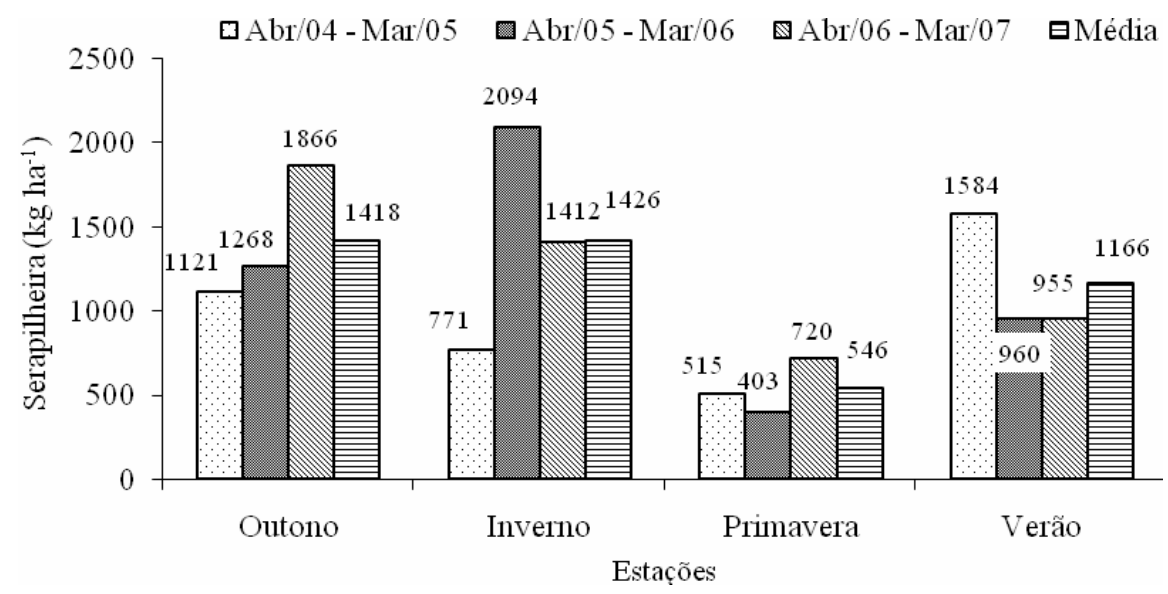

FIGURA 6: Variação estacional da deposição de serapilheira $\left(\mathrm{kg} \mathrm{ha}^{-1}\right)$, em um povoamento de Pinus taeda, em área de segunda rotação. Abr/2004 a Mar/2007. Cambará do Sul, RS.

FIGURE 6: Seasonal litter deposition variation $\left(\mathrm{kg} \mathrm{ha}^{-1}\right)$, in a Pinus taeda stand, in a second rotation area. April/2004 to March/2007. Cambará do Sul, RS.

Para Poggiani (1985), a derrubada de acículas mais intensa estaria relacionada com períodos em que a umidade do solo se torna muito baixa. Autores como Gisler (1995) e Martins e Rodrigues (1999) sugerem que o estresse hídrico seja uma causa da queda sazonal de material de árvores em muitas florestas.

Dias et al. (2002) e Oliveira Filho (1987) mencionam que a maior produção de serapilheira, nos meses mais frios e secos do ano, seria uma característica típica de florestas tropicais estacionais e, ao contrário, maior deposição na transição entre estação seca e chuvosa, seria típico de regiões tropicais e subtropicais.

Segundo Brun et al. (2001), a temperatura influência de maneira mais marcante a deposição, de forma que as maiores quedas de serapilheira ocorram nos meses de temperatura elevada. Mas há também uma tendência de uma maior devolução de serapilheira para o piso florestal do povoamento, quando há maior disponibilidade de água.

\section{Transferência de nutrientes ao solo via serapilheira}

\section{Teores de nutrientes na serapilheira}

Na Tabela 4, verificam-se os diferentes teores, de macronutrientes (N, P, K, Ca, Mg e S) contidos na serapilheira. Ocorreu diferença estatística nos teores de macronutrientes, entre os diferentes anos de estudo, somente para o $\mathrm{N}$ e o Ca.

Dentre todos os nutrientes, o Ca foi o que apresentou o maior teor médio. Segundo Clevelário Jr. (1996 apud BORÉM e RAMOS, 2002), o enriquecimento em cálcio na serapilheira pode ser decorrente de uma liberação mais lenta deste elemento pelo material recém caído, da retranslocação de outros elementos antes da abscisão e/ou conseqüência da retenção de Ca contido na transprecipitação (chuva que atravessa o 
dossel) pela serapilheira.

Segundo Dias et al. (2002), o cálcio é um elemento considerado imóvel, isto faz com que ele fique armazenado em forma de cristais na folha, permanecendo nela mesmo em sua senescência. Dessa forma, os plantios de pínus, absorvendo, via sistema radicular, o Ca de maiores profundidades e o devolvendo, via serapilheira, na superfície do solo, podem atuar melhorando a fertilidade deste, uma vez que disponibiliza esse elemento para ser reabsorvido pelas raízes finas que permeiam a camada de serapilheira acumulada ou estão na camada mais superficial do solo.

TABELA 4: Teores de macronutrientes na serapilheira de um povoamento de Pinus taeda, em área de segunda rotação. Cambará do Sul, RS.

TABLE 4: Litter macronutrients contents in a Pinus taeda stand, in a second rotation area. Cambará do Sul RS.

\begin{tabular}{lllllllll}
\hline \multirow{2}{*}{ Período } & \multicolumn{7}{c}{ Macronutrientes $\left(\mathrm{g} \mathrm{kg}^{-1}\right)$} \\
\cline { 2 - 7 } & \multicolumn{1}{c}{$\mathrm{N}$} & \multicolumn{1}{c}{$\mathrm{P}$} & \multicolumn{1}{c}{$\mathrm{K}$} & \multicolumn{1}{c}{$\mathrm{Ca}$} & \multicolumn{1}{c}{$\mathrm{Mg}$} & \multicolumn{1}{c}{$\mathrm{S}$} \\
\hline \multirow{2}{*}{ Abr/04 - Mar/05 } & $5,47 \mathrm{~b}$ & $0,39 \mathrm{a}$ & $1,00 \mathrm{a}$ & $8,53 \mathrm{a}$ & $1,09 \mathrm{a}$ & $0,50 \mathrm{a}$ \\
& $( \pm 0,61)$ & $( \pm 0,06)$ & $( \pm 0,21)$ & $( \pm 2,55)$ & $( \pm 0,24)$ & $( \pm 0,11)$ \\
Abr/05 - Mar/06 & $6,59 \mathrm{ab}$ & $0,45 \mathrm{a}$ & $0,95 \mathrm{a}$ & $5,57 \mathrm{~b}$ & $1,06 \mathrm{a}$ & $0,51 \mathrm{a}$ \\
& $( \pm 1,55)$ & $( \pm 0,13)$ & $( \pm 0,36)$ & $( \pm 1,05)$ & $( \pm 0,09)$ & $( \pm 0,10)$ \\
\multirow{2}{*}{ Abr/06 - Mar/07 } & $6,96 \mathrm{a}$ & $0,44 \mathrm{a}$ & $1,23 \mathrm{a}$ & $5,76 \mathrm{~b}$ & $1,07 \mathrm{a}$ & $0,56 \mathrm{a}$ \\
& $( \pm 1,68)$ & $( \pm 0,06)$ & $( \pm 0,30)$ & $( \pm 1,04)$ & $( \pm 0,16)$ & $( \pm 0,16)$ \\
\hline Média anual & 6,34 & 0,43 & 1,06 & 6,62 & 1,07 & 0,52 \\
\hline CV (\%) & 23,26 & 21,13 & 29,49 & 32,42 & 15,87 & 23,58 \\
\hline
\end{tabular}

Em que: Médias seguidas pela mesma letra, na vertical, não diferem entre si pelo teste de Tukey, a 5\% de probabilidade de erro. Valores entre parênteses, referem-se ao desvio-padrão da média.

Os teores de $\mathrm{P}, \mathrm{K}$ e $\mathrm{Mg}$ foram bastante baixos, devido a baixa disponibilidade desses elementos no solo da região (Tabela 1) em conseqüência da elevada acidez deste. Segundo Borém e Ramos (2002), para o $\mathrm{Ca}, \mathrm{Mg}, \mathrm{K}$ e $\mathrm{P}$, a quantidade contida na serapilheira é comparável à quantidade disponível desse elemento no solo, nos primeiros dez centímetros. Sendo que, no caso do $\mathrm{K}$ e do Mg, eles podem sofrer lixiviação através da água da chuva que atravessa o dossel e permeia a serapilheira, o que poderia explicar os teores baixos desses elementos nesta.

Na Tabela 5, encontram-se os diferentes teores de micronutrientes (B, Cu, Fe, Mn e Zn) contidos na serapilheira. Ocorreu diferença estatística nos teores de micronutrientes, nos diferentes anos de estudo, somente para o B, Fe e Zn.

TABELA 5: Teores de micronutrientes na serapilheira de um povoamento de Pinus taeda, em área de segunda rotação. Cambará do Sul, RS.

TABLE 5: Litter micronutrients contents in a Pinus taeda stand, in a second rotation area. Cambará do Sul RS.

\begin{tabular}{l|cccccc}
\hline \multirow{2}{*}{ Período } & \multicolumn{5}{c}{ Micronutrientes $\left(\mathrm{mg} \mathrm{kg}^{-1}\right)$} \\
\cline { 2 - 6 } & $\mathrm{B}$ & $\mathrm{Cu}$ & $\mathrm{Fe}$ & $\mathrm{Mn}$ & $\mathrm{Zn}$ \\
\hline \multirow{2}{*}{ Abr./04-mar./05 } & $10,76 \mathrm{~b}$ & $3,67 \mathrm{a}$ & $309,17 \mathrm{a}$ & $1725,06 \mathrm{a}$ & $37,33 \mathrm{a}$ \\
& $( \pm 3,25)$ & $( \pm 0,97)$ & $( \pm 96,41)$ & $( \pm 535,37)$ & $( \pm 12,08)$ \\
Abr./05-mar./06 & $15,92 \mathrm{a}$ & $4,13 \mathrm{a}$ & $208,03 \mathrm{~b}$ & $1307,69 \mathrm{a}$ & $27,70 \mathrm{~b}$ \\
& $( \pm 3,54)$ & $( \pm 1,70)$ & $( \pm 54,57)$ & $( \pm 210,38)$ & $( \pm 6,49)$ \\
Abr./06-mar./07 & $13,65 \mathrm{ab}$ & $3,87 \mathrm{a}$ & $187,44 \mathrm{~b}$ & $1563,36 \mathrm{a}$ & $34,09 \mathrm{ab}$ \\
& $( \pm 2,24)$ & $( \pm 1,04)$ & $( \pm 95,37)$ & $( \pm 471,94)$ & $( \pm 4,43)$ \\
\hline Média anual & 13,45 & 3,89 & 234,88 & 1532,03 & 33,04 \\
\hline \multicolumn{1}{c}{ CV $(\%)$} & 27,26 & 32,37 & 41,77 & 29,51 & 27,36 \\
\hline
\end{tabular}

Em que: Médias seguidas pela mesma letra, na vertical, não diferem entre si pelo teste de Tukey, a 5\% de probabilidade de erro. Valores entre parênteses, referem-se ao desvio-padrão da média.

Dentre os micronutrientes, o manganês apresentou o maior teor médio anual (1.532 mg kg-1), sendo maior do que alguns macronutrientes (P, S, K e Mg). O Mn e o Fe apresentaram teores bem superiores que o $\mathrm{B}$, Cu e Zn. 
Teores elevados de Fe e Mn são decorrentes das altas concentrações destes elementos no solo (Tabela 1), causando toxidez a um bom número de espécies vegetais. Plantas de pinus, adaptadas a este tipo de condição, conseguem apresentar bom crescimento, o que pode ser ainda maior, quando são realizadas práticas de adubação e correção de pH.

\section{Quantidade de nutrientes na serapilheira}

Na Tabela 6, é apresentada a transferência de nutrientes através da serapilheira ao solo do sítio florestal, durante os 3 anos de estudo. O cálcio, por ser o de maior teor na serapilheira, foi o mais fornecido em quantidade ao piso florestal do povoamento. Considerando a transferência de $\mathrm{Ca}+\mathrm{N}$, isso corresponde a mais de $80 \%$ do total de macronutrientes devolvidos ao solo.

Nesse sentido, a magnitude de transferência de macronutrientes ao solo do povoamento foi: $\mathrm{Ca}>\mathrm{N}>$ $\mathrm{Mg}>\mathrm{K}>\mathrm{S}>\mathrm{P}$. No estudo realizado por Melo e Resck (2002), com procedências de Pinus caribaea, com 16 anos de idade, a magnitude foi a seguinte: $\mathrm{N}>\mathrm{Ca}>\mathrm{K}>\mathrm{Mg}>\mathrm{S}>\mathrm{P}$, sendo essa seqüência, segundo Haag (1985), constatada na maioria dos estudos. Em três sítios diferentes (bom, médio e ruim) de Pinus taeda, Koehler (1989), encontrou essa mesma tendência.

TABELA 6: Transferência de nutrientes ao solo, por meio da serapilheira em um povoamento de Pinus taeda, em área de segunda rotação. Cambará do Sul, RS.

TABLE 6: Nutrients transfer to the soil, through litter in a Pinus taeda stand, in a second rotation area, Cambará do Sul, RS.

\begin{tabular}{l|cccccc|c|c|c|c|c|c}
\hline \multirow{2}{*}{ Período } & \multicolumn{4}{|c|}{ Macronutrientes $\left(\mathrm{kg} \mathrm{ha}^{-1}\right)$} & \multicolumn{5}{c}{ Micronutrientes $\left(\mathrm{g} \mathrm{ha}^{-1}\right)$} \\
\cline { 2 - 13 } & $\mathrm{N}$ & $\mathrm{P}$ & $\mathrm{K}$ & $\mathrm{Ca}$ & $\mathrm{Mg}$ & $\mathrm{S}$ & $\mathrm{B}$ & $\mathrm{Cu}$ & $\mathrm{Fe}$ & $\mathrm{Mn}$ & $\mathrm{Zn}$ \\
\hline Abr./04-mar./05 & 21,3 & 1,5 & 3,9 & 33,1 & 4,4 & 2,1 & 40,2 & 14,0 & 1292,8 & 6723,4 & 135,9 \\
Abr./05-mar./06 & 29,7 & 1,9 & 4,2 & 26,5 & 5,1 & 2,5 & 75,0 & 17,0 & 963,2 & 6106,5 & 125,6 \\
Abr./06-mar./07 & 30,8 & 2,1 & 5,5 & 26,5 & 4,9 & 2,5 & 64,9 & 19,0 & 1022,9 & 7239,2 & 166,7 \\
\hline Média anual & 27,27 & 1,9 & 4,6 & 28,7 & 4,8 & 2,4 & 60,0 & 16,7 & 1092,9 & 6689,7 & 142,8 \\
\hline Total & 81,8 & 5,5 & 13,7 & 86,1 & 14,4 & 7,2 & 180,1 & 50,0 & $3.278,8$ & $2.0069,1$ & 428,3 \\
\hline
\end{tabular}

Dentre os micronutrientes, o manganês foi o mais devolvido, também em função de sua maior concentração, em relação aos demais. Considerando a transferência de $\mathrm{Mn}+\mathrm{Fe}$, isso corresponde a mais de $97 \%$ do total de micronutrientes devolvidos ao solo, durante o período de estudo. Nesse sentido a magnitude de transferência de micronutrientes ao solo do povoamento foi: $\mathrm{Mn}>\mathrm{Fe}>\mathrm{Zn}>\mathrm{B}>\mathrm{Cu}$. Entretanto, Melo e Resck (2002) estudando procedências diferentes de Pinus caribaea, com 16 anos de idade, encontrou a seguinte magnitude: $\mathrm{Fe}>\mathrm{Mn}>\mathrm{Zn}>\mathrm{Cu}$.

\section{CONCLUSÕES}

A deposição média anual de serapilheira encontrada neste estudo foi de 4,52 $\mathrm{Mg} \mathrm{ha}^{-1}$, totalizando 13,56 $\mathrm{Mg} \mathrm{ha}^{-1}$ para o período de 3 anos ( $5^{\circ}$ ao $7^{0}$ ano). Isso demonstra a importância dessa via de ciclagem de nutrientes para a manutenção da produtividade do sítio, além de diminuir o efeito da erosão provocada pela incidência da alta intensidade de chuvas na região.

A deposição não se mostrou com tendência sazonal nítida, possuindo a seguinte ordem estacional média: inverno $=$ outono $>$ verão $>$ primavera.

A análise efetuada entre deposição de serapilheira e variáveis climáticas, não apresentaram correlações satisfatórias durante o período de estudo.

O cálcio, entre os macronutrientes, e o manganês, entre os micronutrientes, apresentaram as maiores concentrações entre os nutrientes que retornam ao solo via deposição de serapilheira.

A transferência total de macronutrientes ao solo, por meio da deposição da serapilheira, para os 3 anos de estudos, foi de: 86,14 de Ca; 81,81 de N; 14,42 de Mg; 13,71 de K; 7,16 de S e 5,54 de P, em kg ha ${ }^{-1}$ e a transferência de micronutrientes, foi de: 20069,10 de Mn; 3278,83 de Fe; 428,30 de Zn; 180,12 de B e 49,98 de Cu, em $\mathrm{g} \mathrm{ha}^{-1}$.

\section{REFERÊNCIAS BIBLIOGRÁFICAS}

ABRAF. Anuário estatístico da ABRAF: ano base 2006/ABRAF. Brasília, 2007, 80p.

BORÉM, R. A.T.; RAMOS, D. P. Variação estacional e topográfica de nutrientes na serapilheira de um fragmento de 
mata atlântica. Cerne, Lavras, v. 8, n. 2, p. 042-059, 2002.

BRASIL. Ministério da Agricultura. Divisão de Pesquisa Pedológica DNPEA. Levantamento de reconhecimento dos solos do Estado do Rio Grande do Sul. Recife, 1973. 431p. (Boletim Técnico, 30).

BRAY, J. R.; GHORAN, E. Litter production in forest of the world. Advances in Ecological Research, Londres, v. 2, 1964, p. 101-157.

BRUN, E. J.; SCHUMACHER, M. V.; VACCARO, S.; et al. Relação entre a produção de serapilheira e variáveis meteorológicas em três fases sucessionais de uma floresta Estacioanal Decidual no Rio Grande do Sul. Rev. Bras. Agrometeorologia, Santa Maria, v. 9, n. 2, p. 277-285, 2001.

CRUZ, C.D. Programa Genes - Aplicativo Computacional em Genética e estatística. Versão 2001.0.0 for Windows, 2001.

DIAS, H. C. T.; FIGUEIRA, M. D.; SILVEIRA, V. et al. Variação temporal de nutrientes na serapilheira de um fragmento de Floresta Estacional Semidecidual em Lavras, Minas Gerais - Brasil. Cerne, Lavras, v. 8, n. 2, p. 001-016, 2002.

Fundação de economia e estatística (FEE) do estado do Rio Grande do Sul. Disponivel em: (http://www.fee.tche.br/sitefee/pt/content/resumo/pg_municipios_detalhe.php?municipio=Cambar\%E1+do+Sul) > Acesso em: 15 de outubro de 2008.

FERREIRA, C. A.; SILVA, H. D.; BELlOTE, A. F. J.; et al. Pesquisa sobre nutrição de pinus no sul do Brasil. Revista da Madeira, Curitiba, n. 83, ano 14, agosto de 2004.

GISLER, C. V. T. O uso da serapilheira na recomposição da cobertura vegetal em áreas mineradas de bauxita, em Poços de Caldas, MG. São Paulo: USP, 1995. 146 p. Dissertação (Mestrado em Ecologia) - Universidade de São Paulo. Instituto de Biociências, 1995.

HAAG, H. P. Ciclagem de nutrientes em florestas tropicais. Campinas: Fundação Cargill, 1985. 144 p.

KOEHLER, W. C. Variação estacional de deposição de serapilheira e de nutrientes em povoamentos de Pinus taeda na região de Ponta Grossa-PR. Curitiba: UFPR, 1989. 138p. Tese (Doutorado em Ciências Florestais). Universidade Federal de Paraná, 1989.

MARTINS, S. V.; RODRIGUES, R. R. Produção de serapilheira em clareiras de uma floresta estacional semidecidual no município de Campinas, S. P. Revista Brasileira de Botânica, São Paulo, v. 22, n. 3, p. 405-412, 1999.

MELO, J. T.; RESCK, D. V. S. Retorno, ao solo, de nutrientes de serapilheira de pinus no cerrado do Distrito Federal. Planantina, DF: Embrapa Cerrados, 2002. 18p. (Boletim de pesquisa e desenvolvimento / Embrapa Cerrados, n. 75).

MORENO, J. A. Clima do Rio Grande do Sul. Porto Alegre: Secretaria da Agricultura, 1961. 42p.

MOTTA, F. S.; BEISDORF, M. J. C.; GARCEZ, R.B. Zoneamento agrícola do Rio Grande do Sul e Santa Catarina: normas agro-climáticas. Pelotas: Ministério da Agricultura, 1971. 80p.

OLIVEIRA, R. R. Produção e decomposição de serapilheira no Parque Nacional da Tijuca, RJ. Rio de Janeiro: IG, 1987. 107 p. Dissertação (Mestrado em Geografia) - Departamento de Geografia. Instituto de Geociências, 1987.

PEREIRA, A. R.; BARROS, N. F. de; ANDRADE, D. C. et al. Concentração e distribuição de nutrientes em Eucalyptus grandis em função da idade, cultivado na região do Cerrado. Brasil Florestal, Brasília, v. 13, n. 59, 1984.

POGGIANI, F. Ciclagem de nutrientes em ecossistemas de plantações florestais de Eucalyptus e Pinus: implicações silviculturais. Piracicaba: ESALQ, 1985. 229p. Tese (Livre docência) Escola Superior de Agricultura Luiz de Queiroz / USP, 1985.

POGGIANI, F.; ZAMBERLAN, E.; MONTEIRO JR., E. et al.. Quantificação da deposição de folhedo em talhões experimentais de Pinus taeda, Eucalyptus viminalis e Mimosa scabrella plantados em uma área degradada pela mineração do xisto betuminoso. IPEF, Piracicaba, v. 47, p. 21-29, 1987.

REIS, M. G. F.; BARROS, N. F. Ciclagem de nutrientes em plantios de eucalipto. In: BARROS, N. F.; NOVAIS R. F. (eds.). Relação Solo Eucalipto. Ed. Folha de Viçosa, Viçosa, MG; 1990 p. 265-301.

SCHUMACHER, M. V.; BRUN, E. J.; KÖNIG, F. G. Análise de nutrientes para a sustentabilidade. Revista da Madeira, Curitiba, n. 83, ano 14, agosto de 2004.

SCHUMACHER, M. V.; PISSININ, L. Z.; VIERA, M. et al. Monitoramento das características físicas e químicas do solo em área de segunda rotação com floresta de Pinus taeda L. Santa Maria, Departamento de Ciências Florestais, UFSM, 29p. (Relatório parcial de pesquisa), 2007.

STRECK, E. V.; KÄMPF, N.; DALMOLIN, R. S. D. et al. Solos do Rio Grande do Sul. Porto Alegre: EmaterRS/UFRGS, 2002, 107p.

TEDESCO, M.J.; GIANELLO,C.; BISSANI, C. A. et al. Análise de solo, plantas e outros materiais. Porto Alegre, Departamento de Solos, UFRGS. 118 p. (Boletim Técnico). 1995.

VITAL, A. R. T.; GUERRINI, I. A.; FRANKEN, W. K. et al. Produção de serapilheira e ciclagem de nutrientes de uma floresta estacional semidecidual em zona ripária. Revista Árvore, Viçosa, v. 28, n. 6, p. 793-800, 2004. 